\title{
Initiation of a Greenhouse Gas Monitoring System in New York City
}

\author{
Dickens St. Hilaire ${ }^{1}$, Philippe Mercier $^{2 *}$, Neal Phillip ${ }^{1}$ \\ ${ }^{1}$ Department of Chemistry and Chemical Technology, Bronx Community College of the City University of New York, New York, US \\ ${ }^{2}$ Department of Natural Science, LaGuardia Community College of the City University of New York, New York, US \\ Email: *pmercier@lagcc.cuny.edu
}

How to cite this paper: St. Hilaire, D., Mercier, P. and Phillip, N. (2019) Initiation of a Greenhouse Gas Monitoring System in New York City. Atmospheric and Climate Sciences, 9, 26-34. https://doi.org/10.4236/acs.2019.91002

Received: September 12, 2018 Accepted: December 10, 2018 Published: December 13, 2018

Copyright (c) 2019 by authors and Scientific Research Publishing Inc. This work is licensed under the Creative Commons Attribution International License (CC BY 4.0).

http://creativecommons.org/licenses/by/4.0/

\section{(c) (i) Open Access}

\begin{abstract}
Highly urbanized and industrialized cities across the globe have been known for a long time to be major anthropogenic sources of greenhouse gases (GHGs), yet there is still no consensus on an adequate methodology to monitor their ambient concentration. This work describes the initiation of a GHG monitoring program at Bronx Community College (BCC) of the City University of New York (CUNY) in Bronx, New York using a Picarro GHG monitor (Model g2301). Results show average atmospheric levels of carbon dioxide $\left(\mathrm{CO}_{2}\right)$ and methane $\left(\mathrm{CH}_{4}\right)$ that are above 400 and $2.0 \mathrm{ppmv}$, respectively. Similar daily fluctuations, with peaks levels resulting from emissions likely occurring during morning rush hour, indicate that there are common sources for both gases. This monitoring system is replicable, sustainable and scalable and will make it possible to more quantifiably link emissions produced in New York City to their material sources. As more data is collected, reduction projections for GHG-producing materials will more accurately be associated to reduction projections for atmospheric $\mathrm{CO}_{2}$ and $\mathrm{CH}_{4}$ levels originating in New York City. In the process, empirical models on air exchange rates and convective boundary layer homogenization through turbulence could also be improved.
\end{abstract}

\section{Keywords}

Greenhouse Gases, Methane, Carbon Dioxide, Anthropogenic Sources, New York City, NYC

\section{Introduction}

Over the past few decades, evidence has mounted that planetary-scale environmental changes are occurring primarily as a result of relatively recent large-scale and rapid industrialization. These changes range from the artificial fixation of 
nitrogen and the emission of greenhouse gas (GHGs) to the conversion and fragmentation of natural vegetation and the loss of biological species. It is such activities that give rise to the phenomenon of global change [1]. These concerns have led to much research to monitor, sequester, and mitigate the amounts of these substances in the atmosphere. To that end, there has been much research done worldwide over the decades to track anthropogenic gases, especially $\mathrm{CO}_{2}$, as begun by the pioneering work of Dave Keeling who began monitoring $\mathrm{CO}_{2}$ at Mauna Loa, Hawaii and the South Pole, Antarctica in the 1950s. Keeling's research provided reliable data on the progressive rise in $\mathrm{CO}_{2}$ levels over the decades and was very important in establishing awareness of the link between rising $\mathrm{CO}_{2}$ levels and rising global average temperatures [2]-[7]. It is feared that the continuously increasing levels of GHGs in the atmosphere along with other anthropogenic and volatile compounds, mainly originating from urban and highly industrialized centers, will eventually lead to irreversible increases in average global temperatures. Despite urban areas representing a small proportion of the total land mass, they are responsible for the majority of GHG emissions [8] [9] [10] [11]. It is therefore very crucial to gear efforts toward reducing GHG emission levels in urban areas. Since 2006, New York City (NYC) has actively participated in the Global Protocol for Community-Based Greenhouse Gas Emission Inventories (GPC) in order to track the amount and sources of GHG, as well as the mechanisms by which these gases eventually reach the atmosphere. Through this protocol NYC has determined natural gas and petroleum to be the principal culprits; approximately $73 \%$ and $21 \%$ of GHGs are emitted by buildings and from transportation sources, respectively [12]. NYC is using this information to devise ways to reduce greenhouse gas production and emissions down to $20 \%$ by 2050 . Unfortunately, an important fact was overlooked when these projections were made. The relationship between the amount of material used at the GHG sources and the actual amount of GHG added to atmospheric levels is neither direct nor linear. The relationship is very complex; for instance, certain mitigation efforts may efficiently reduce the amount of material needed while simultaneously producing just as much greenhouse gas. The result is that cities participating in the GPC may actually meet or exceed their target consumption reduction projections and nonetheless observe a poor reduction in actual atmospheric greenhouse gas levels, if at all. Once the gases are produced, other methods and strategies are needed to further reduce GHG levels before they reach the atmosphere. Since Keeling's work, much of the research conducted has largely been tailored for very specific regions and environmental settings, making them limited in scope, applicability or scalability. Only recently has work been done to develop replicable and scalable monitoring systems that track emission levels of anthropogenic gases [13] [14] [15]. Such work is essential to understand how human activity and behavior directly contribute to increases in GHG levels, particularly in highly urbanized environments such as New York City. The results obtained here begin to provide meaningful data to improve air exchange rate models [16] which are crucial to connecting the con- 
sumption of GHG-producing materials to the actual contributions made to atmospheric GHG levels. In this paper, we report some initial data from a GHG monitoring system begun at Bronx Community College in New York City.

This work focuses on examining the average daily fluctuations in $\mathrm{CO}_{2}$ and $\mathrm{CH}_{4}$ atmospheric levels from April 2016 to December 2017, particularly as it relates to data reported by the City of New York in its GHG inventory. The results of this work have shown that $\mathrm{CO}_{2}$ and $\mathrm{CH}_{4}$ levels fluctuate similarly, suggesting common sources for both gases; additionally, average levels appear to be consistent with levels observed globally. Fluctuations in water vapor levels at this site are also presented. Sustained data-collection of this type will make it possible to empirically improve atmospheric air exchange rate models, including those that are related to understanding the homogenizing effect of turbulence in the convective boundary layer on GHG concentrations [17] [18], and improve reduction projections of atmospheric GHG produced in major urban centers such as New York City.

\section{Experimental Methods and Materials}

\section{Picarro Instrument}

Picarro Cavity Ring-Down Spectroscopy (CRDS, Model G2301) Analyzer (for $\mathrm{CO}_{2} / \mathrm{CH}_{4} / \mathrm{H}_{2} \mathrm{O}$ in air) was used as shown in Figure 1. It is an infrared spectrometer that uses a three-mirror cavity that analyzes the decay rate profile of a laser signal whose wavelength is absorbed by a gas, relative to the decay rate profile of an unabsorbed wavelength. The cavity has a path length of $25 \mathrm{~cm}$, and after the laser signal reaches a threshold level, it is shut off and the light cycles approximately one hundred thousand times within the cavity during the decay process. The cycling produces an effective absorption path length in the vicinity of $20 \mathrm{~km}$ and makes it possible for the Picarro CRDS model G2301 to measure the greenhouse gases down to parts-per-billion (ppbv) sensitivity. The system is sufficiently robust to provide continuous, months-long data collection. Picarro's G2301 analyzer enables measurement of dry-gas mixing ratios for carbon dioxide and methane directly in the wet gas stream, an important factor that allows for immediate data analysis without the need for extrapolation of data to dry air conditions. A customized Python program was made by the manufacturer in order to convert the raw.txt files into Excel-ready files for graphing and other analysis. As shown in Figure 2, the Picarro greenhouse gas monitor is located on the rooftop of Meister Hall at the Bronx Community College (BCC), CUNY that continuously measures the three GHGs. Additionally, the Picarro system also monitors temperature, pressure, solar radiation, wind direction, wind speed, and humidity.

\section{Results/Discussion}

Figure 3 shows average monthly $\mathrm{CO}_{2}$ and $\mathrm{CH}_{4}$ atmospheric levels from April 2016 to December 2017 with the exception of data between November 2016 and 


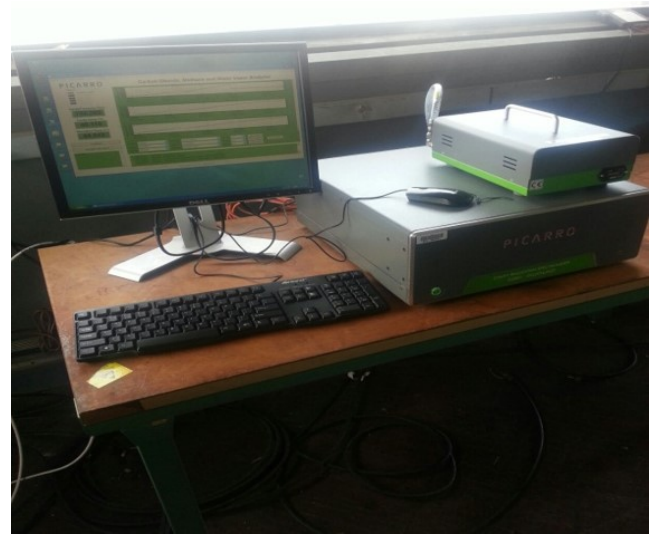

Figure 1. Picarro instrument and computer setup.

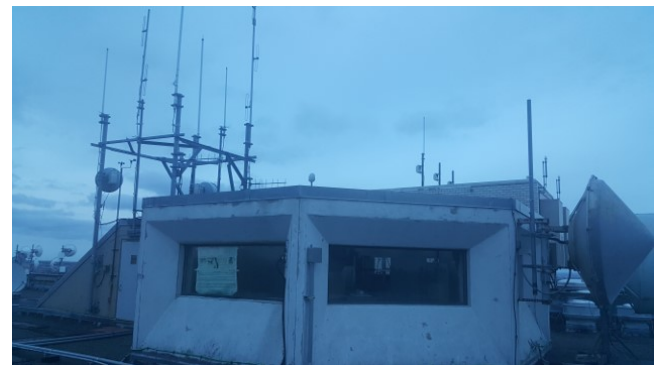

Figure 2. Picarro detection system on the rooftop.

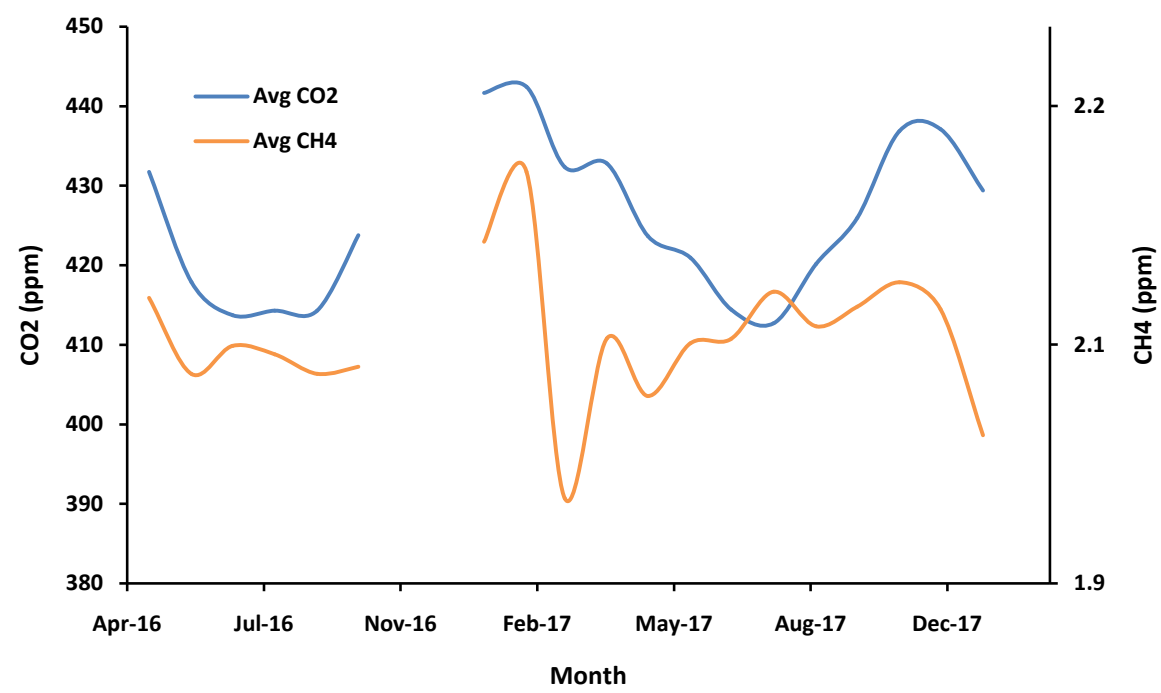

Figure 3. Average monthly $\mathrm{CO}_{2}$ and $\mathrm{CH}_{4}$ atmospheric levels from April 2016 to December 2017 (Data between November 2016 to January 2017 were not recorded).

January 2017, which failed to be recorded. The greenhouse gas levels reach their highest in the winter months and their lowest during summer months, consistent with known data on seasonal variations in atmospheric $\mathrm{CO}_{2}$ and $\mathrm{CH}_{4}$ worldwide.

Figure 4 shows average weekly $\mathrm{CO}_{2}$ and $\mathrm{CH}_{4}$ atmospheric levels for the months of January 2017 (a), May 2017 (b), July 2017 (c), and November 2017 


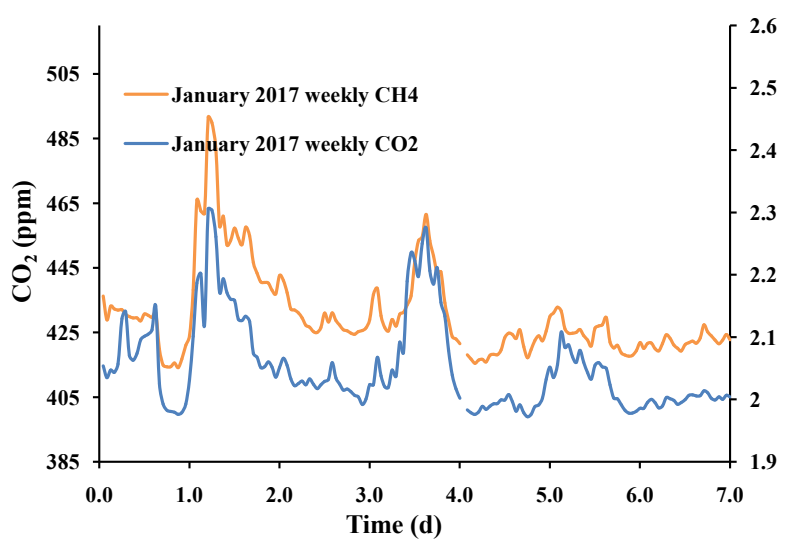

(a)

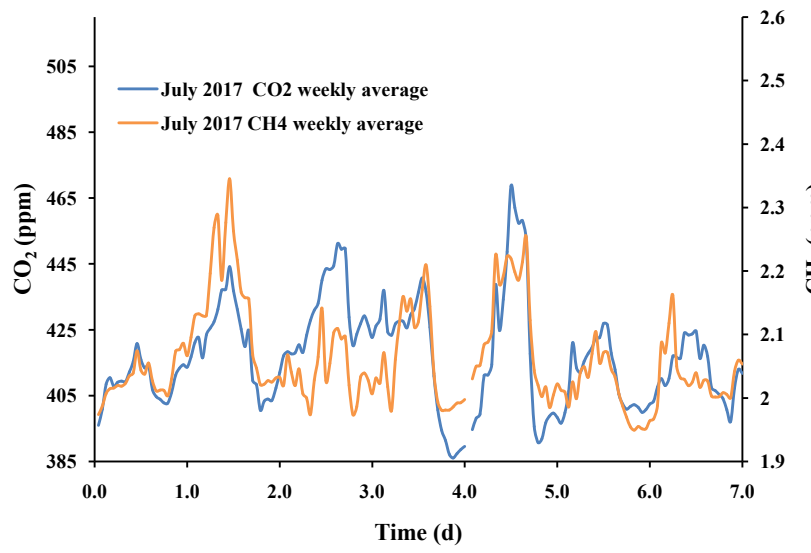

(c)

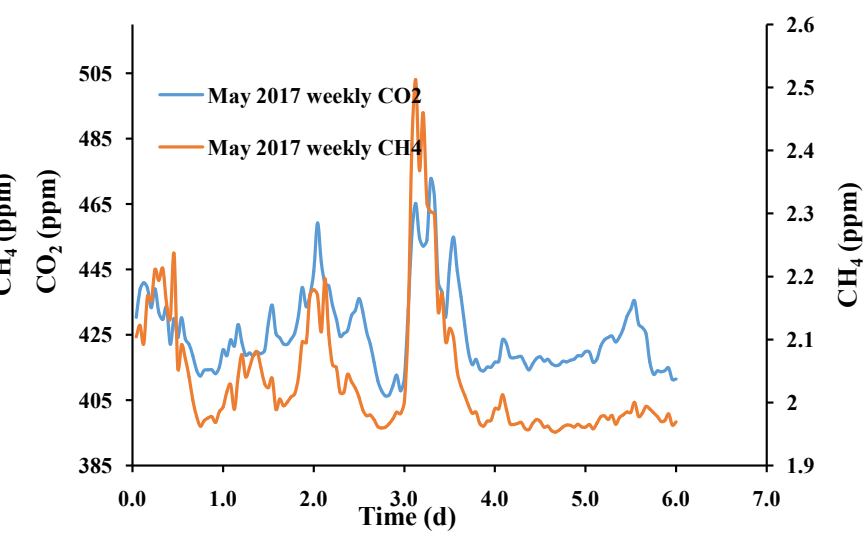

(b)

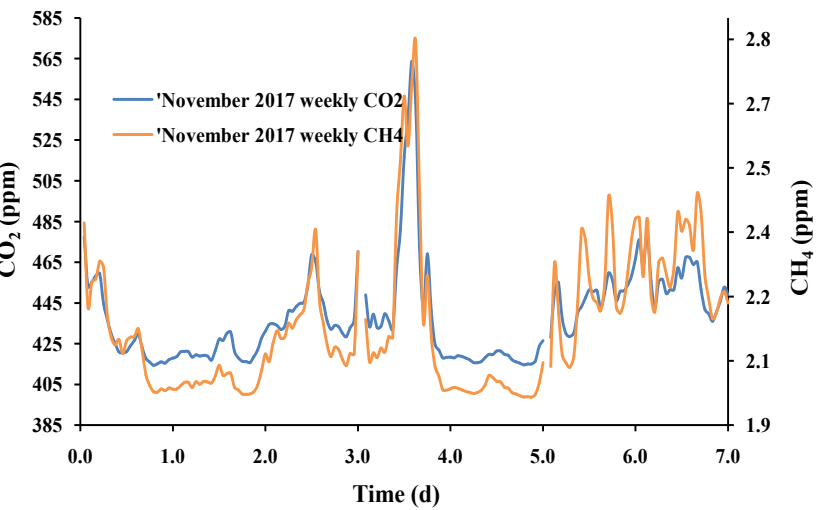

(d)

Figure 4. (a)-(d) Average weekly $\mathrm{CO}_{2}$ and $\mathrm{CH}_{4}$ atmospheric levels during the months of January 2017 (a), May 2017 (b), July 2017 (c), and November 2017 (d).

(d). The data for each month was representative of results obtained for other winter, spring, summer, and fall months, respectively. GHG have many common sources therefore as expected, $\mathrm{CO}_{2}$ and $\mathrm{CH}_{4}$ levels appear to rise and fall at similar moments, with similar degrees of fluctuation between emission peaks and valleys, representing fluctuations of approximately 20 to $40 \mathrm{ppm}$ for $\mathrm{CO}_{2}$ and around $0.2 \mathrm{ppm}$ for $\mathrm{CH}_{4}$. Of the four graphs, the variability in the emission fluctuations is most pronounced in Figure 4(a), in the winter month of January, and is least pronounced in Figure 4(c), in the summer month of July. The seasonal changes in average greenhouse gas levels appear to be largely independent of the fluctuations that occur on a daily basis in New York City whereas the fluctuations themselves appear to be caused by local factors. The daily atmospheric $\mathrm{CO}_{2}$ and $\mathrm{CH}_{4}$ peaks generally appear to occur around midday, however, as research has shown, these increases are likely caused by greenhouse gas emissions that occurred earlier in the day and took time to eventually reach the atmosphere. The length of the time delay depends on conditions such as temperature, wind speed, etc, and will tend to vary day-to-day, however, it is plausible that the morning period between from 6 to $9 \mathrm{am}$, commonly referred to as "rush hour", is when the surge in greenhouse gas emissions occurs. If rush hour is indeed 
when the emission increases occur that would suggest a time delay of approximately three to six hours between the production and eventual mixing of gases in the atmosphere. The delay appears to be shorter during the summer and longer during the winter. It could also be expected that an equivalent emission peak would be caused by emissions occurring during the evening rush hour period that happens between 4 to $7 \mathrm{pm}$, and that the emissions would reach the atmosphere approximately three to six hours later as well. There are some challenges to demonstrating when the second emission surge appears in the data because of many factors, principally the fact that the mechanism that draws the gases into the atmosphere during the day, solar heating, is not present in the evening. The result would be a more diffuse, irregular, and slower propagation of the gases in the evening hours.

In Figures 5(a)-(d), $\mathrm{CO}_{2}$ and $\mathrm{CH}_{4}$ emissions are shown for randomly chosen days during the same months as shown in Figures 4(a)-(d). The emission peaks appear to occur between 10 am to $3 \mathrm{pm}$ with other minor peaks occurring as well, similarly to what was observed in Figure 4 where average atmospheric levels of $\mathrm{CO}_{2}$ and $\mathrm{CH}_{4}$ peaked after sunrise, in the late morning to early afternoon period.

In Figures 6(a)-(d), atmospheric $\mathrm{H}_{2} \mathrm{O}$ levels are compared to $\mathrm{CH}_{4}$ levels for the same days as chosen for the graphs in Figure 3. With the exception of

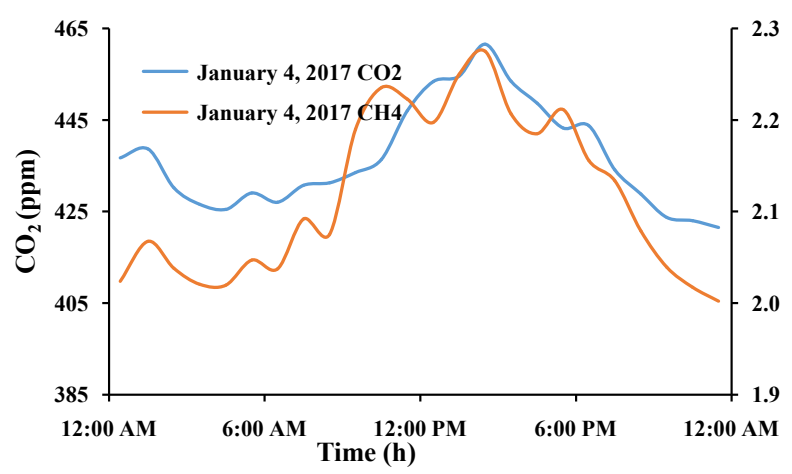

(a)

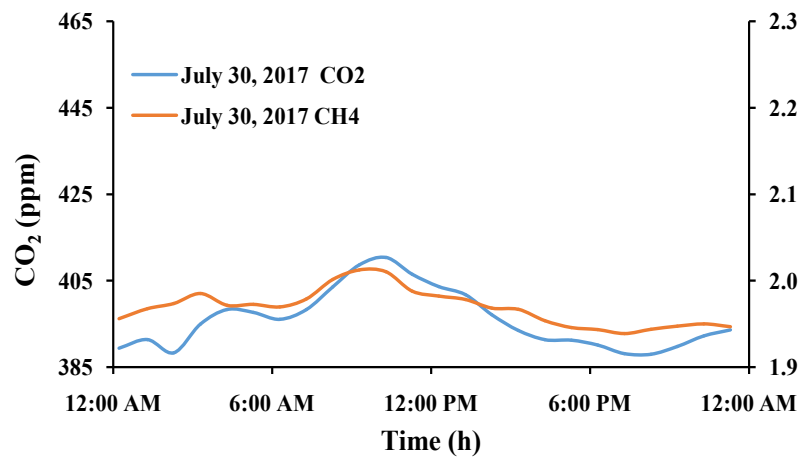

(c)

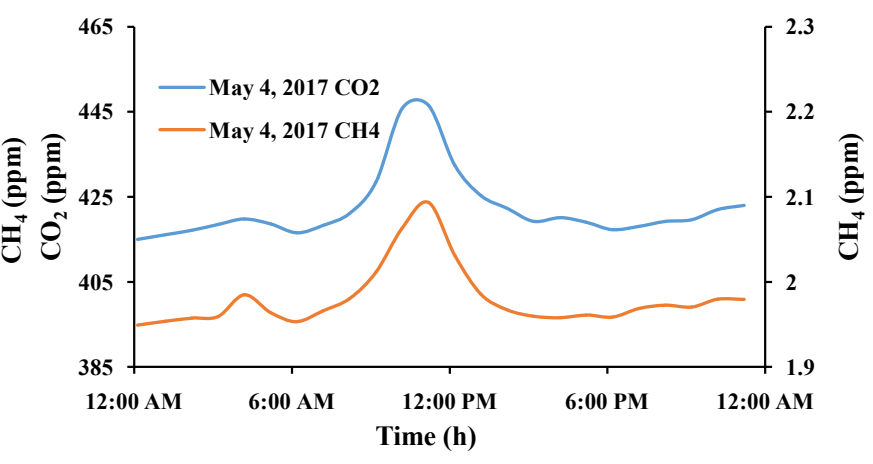

(b)

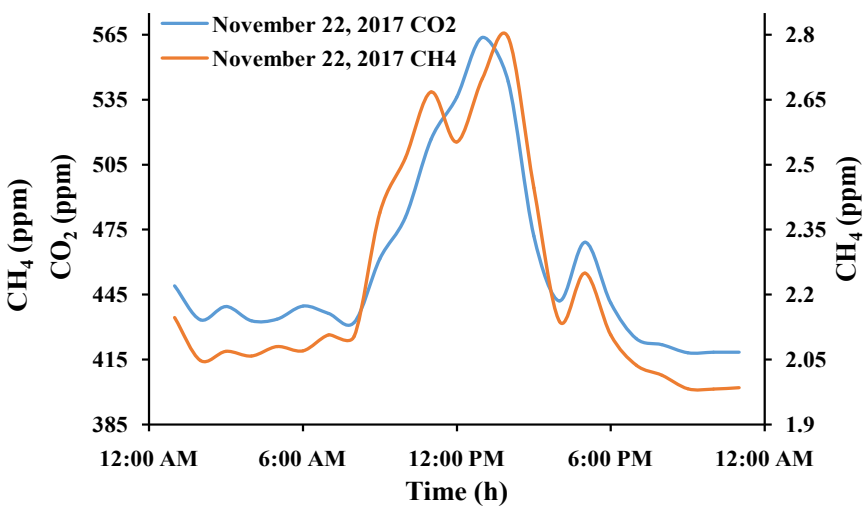

(d)

Figure 5. (a)-(d) $\mathrm{CO}_{2}$ and $\mathrm{CH}_{4}$ atmospheric levels for January 4, 2017 (a), May 4, 2017 (b), July 30, 2017 (c), and November 22, 2017. 


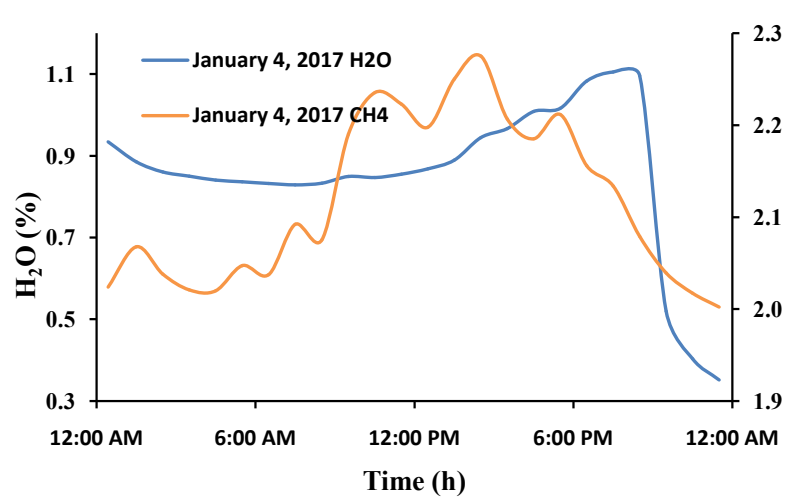

(a)

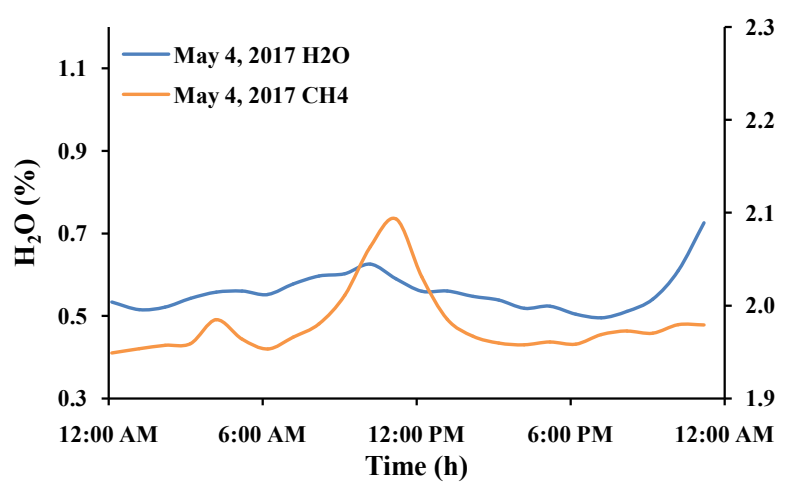

(c)

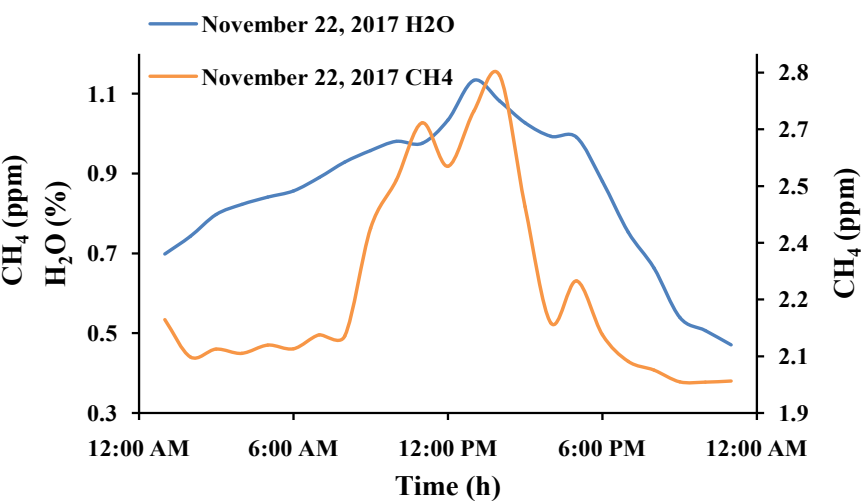

(b)

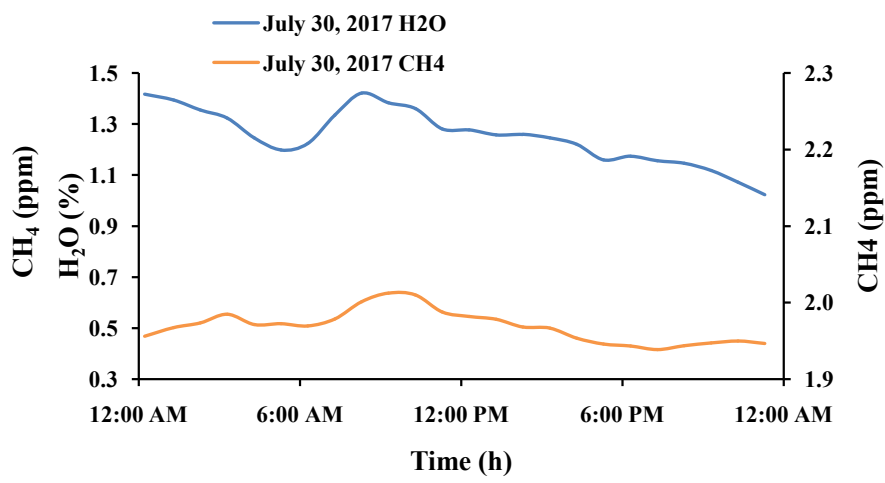

(d)

Figure 6. (a)-(d) $\mathrm{H}_{2} \mathrm{O}$ and $\mathrm{CH}_{4}$ atmospheric levels for January 4, 2017 (a), November 22, 2017 (b), May 4, 2017 (c), and July 30, 2017 (d).

January 4, the levels and fluctuations in $\mathrm{H}_{2} \mathrm{O}$ and $\mathrm{CH}_{4}$ appear to be very similar, again showing that these emissions are being generated in large part from common sources.

Considerations on Modelling:

The total $\mathrm{CO}_{2}$ and $\mathrm{CH}_{4}$ levels above any geographical area comes from the amounts of gases generated within that location that escape into the atmosphere and the net flow of gases into and out. Mathematically, this process can essentially be modelled as a standard mixing problem wherein a quantity of gas flows in, mixes with a quantity of gas already present or generated on site, then exits that area. This model, however, cannot be refined to greater detail and reasonably be expected to reflect actual conditions or predict future trends in greenhouse gas levels because there is insufficient real-time and sustained, long term data collected on which to build. This information is extremely important because it is only when that specific data is obtained that quantifiable projections and reliable estimations on mitigation efforts that target sources of GHG can ultimately be made and be connected to actual atmospheric GHG levels. A crucial component of that work is a determination of the air exchange rates (AER) between indoor and outdoor environments. Up to now there are only very basic, very simplified models in controlled settings that cannot be used to compare to real data because that data is currently unavailable. Another consideration in 
developing better models to track, analyze, and provide more reliable projections, is understanding more fully the role of turbulence in homogenizing the convective boundary layer. The work reported here begins to provide the kind of real-time and sustained data needed to produce better empirically-supported models by eventually making it possible to disaggregate the roles of turbulence, atmospheric air flow, and air-exchange rates in atmospheric GHG level fluctuations.

\section{Conclusion}

In this work, the beginning of a replicable, sustainable, and scalable GHG monitoring system was discussed using $\mathrm{CO}_{2}$ and $\mathrm{CH}_{4}$ atmospheric data over the course of the past 18 months. The data obtained showed an overall upward track in those two GHG levels. Daily fluctuations in GHG levels were attributed to on-site human activity with peak levels likely caused by emissions occurring during morning rush hour, however, continued data collection will be needed to develop better models to disaggregate the primary factors that contribute to daily atmospheric GHG level fluctuations.

\section{Acknowledgements}

We would like to thank the CUNY Office of Research for providing the initial funding to purchase the Picarro Greenhouse gas monitoring instrument. We are eternally grateful to John Rainwater from Picarro for all the technical support he provided to automate the data collection and analysis from the Picarro using Python programming. We are also grateful to our former student Alejandro Prieto who helped install the Picarro instrument. Lastly we we would like to thank our undergraduate research students Augustine Amissah, Abigail Nketsia, and the Department of Chemistry and Chemical Technology for the support on the project.

\section{Conflicts of Interest}

The authors declare no conflicts of interest regarding the publication of this paper.

\section{References}

[1] Geetha, V. (2015) Global Change and Air Pollution. International Journal of Multidisciplinary Advanced Research Trends, 2, 218-233.

[2] Harris, D.C. and David, C. (2010) Keeling and the Story of Atmospheric $\mathrm{CO}_{2}$ Measurements. Analytical Chemistry, 82, 7865-7870. https://doi.org/10.1021/ac1001492

[3] Hegerl, G.C., et al. (2007) Understanding and Attributing Climate Change. In: Solomon, S. and Coauthors, Eds., Climate Change 2007: The Physical Science Basis, Cambridge University Press, Cambridge, 663-745.

[4] Hegerl, G.C. and Zwiers, F.W. (2011) Use of Models in Detection and Attribution of Climate Change. Climate Change, 2, 570-591. https://doi.org/10.1002/wcc.121

[5] Manabe, S. and Wetherland, R.T. (1975) The Effects of Doubling the $\mathrm{CO}_{2}$ Concen- 
trations on the Climate of a General Circulation Model. Journal of the Atmospheric Sciences, 32, 3-15. https://doi.org/10.1175/1520-0469(1975)032<0003:TEODTC>2.0.CO;2

[6] Keeling, C.D., Whorf, T.P., Wahlen, M. and Van Der Plicht, J. (1995) Interannual Extremes in the Rate and Rise of Atmospheric Carbon Dioxide since 1980. Nature, 375, 666-670. https://doi.org/10.1038/375666a0

[7] Keeling, C.D. (1998) Rewards and Penalties of Monitoring the Earth. Annual Review of Energy and the Environment, 23, 25. https://doi.org/10.1146/annurev.energy.23.1.25

[8] Churkina, G. (2008) Modeling the Carbon Cycle of Urban Systems. Ecological Modelling, 216, 107-113. https://doi.org/10.1016/j.ecolmodel.2008.03.006

[9] Potere, D. and Schneider, A. (2007) A Critical Look at Representations of Urban Areas in Global Maps. GeoJournal, 69, 55-80. https://doi.org/10.1007/s10708-007-9102-Z

[10] Grubler, A. (1994) Technology. In: William, B.M. and Turner II, B.L., Eds., Changes in Land Use and Land Cover. A Global Perspective, Cambridge University Press, Cambridge, 287.

[11] O'Meara, M. (1999) Reinventing Cities for People and the Planet, vol. 147. Worldwatch, Washington.

[12] Inventory of New York City Greenhouse Gas Emissions in 2014. https://www1.nyc.gov/assets/sustainability/downloads/pdf/publications/NYC_GHG Inventory_2014.pdf

[13] Chedin, A., Saunders, R., Hollingsworth, A., Scott, N., Matricardi, M., Etcheto, J., Clerbaux, C., Armante, R. and Crevoisier, C. (2003) The Feasibility of Monitoring $\mathrm{CO}_{2}$ from High-Resolution Infrared Sounders. Journal of Geophysical Research, 108, 4064. https://doi.org/10.1029/2001JD001443

[14] Butz, A., Guerlet, S., Hasekamp, O., Schepers, D., Galli, A., Aben, I., Frankenberg, C., Hartmann, J.-M., Tran, H., Kruze, A., Keppel-Aleks, G., Toon, G., Wunch, D. Wennberg, P., Deutscher, N., Griffith, D., Macatangay, R., Messerschmidt, J., Notholt, J. and Warneke, T. (2011) Toward Accurate $\mathrm{CO}_{2}$ and $\mathrm{CH}_{4}$ Observations from GOSAT. Geophysical Research Letters, 38, 1-6. https://doi.org/10.1029/2011GL047888

[15] Gavrilov, N.M., Makarova, M.V., Poberovskii, A.V. and Timpofeyev, Yu.M. (2014) Comparisons of $\mathrm{CH}_{4}$ Ground-Based FTIR Measurements near Saint Petersburg with GOSAT Observations. Atmospheric Measurement Techniques, 7, 1003-1010. https://doi.org/10.5194/amt-7-1003-2014

[16] You, Y., Can, N., Jian, Z., Yating, L., Zhipeng, B., Jiefeng, Z., He, F. and Zhang, N. (2012) Measuremnt of Air Exchange Rates in Different Indoor Environments Using Continuous $\mathrm{CO}_{2}$ Sensors. Journal of Environmental Sciences, 24, 657-664. https://doi.org/10.1016/S1001-0742(11)60812-7

[17] Stull, R.B. (1988) An Introduction to Boundary Layer Meteorology. Kluwer Academic Publishers, Dordrecht.

[18] Van Heerwaarden, C.C. and Mellado, J.P. (2016) Growth and Decay of a Convective Boundary Layer over a Surface with a Constant Temperature. Journal of the Atmospheric Sciences, 73, 2165-2177. https://doi.org/10.1175/JAS-D-15-0315.1 